\title{
Analysis of seismic response on linear viscous damping energy dissipation frame structure
}

\author{
Zhang Min \& Li Yang \\ ${ }^{1}$ School of Civil Engineering and Architecture, Guangxi University of Science and Technology, \\ Liuzhou, Guang Xi, China \\ azhmzm@126.com
}

Keywords: State equation, Vibration, Damp, Damper, Viscous, Seismic

\begin{abstract}
The seismic response on linear viscous damping energy dissipation frame structure is studied. In the vibration equation of seismic action, the damping matrix is not orthogonal to vibration mode of the frame structures installing linear viscous damper. Therefore, the traditional mode decoupling method is no longer suitable for the solution of the vibration equation. The direct integration method of state equation is adopted, by which the seismic response is researched of the frame structure installing linear viscous dampers, and the influence of the arrangement of the dampers on seismic response is investigated. The result indicates that the viscous dampers in the structure should be arranged in structure continuously and uninterruptly, the storey drift angle may be decreased significantly when the dampers are installed in structure continuously, and the damping effect is more significant when viscous dampers are arranged in structure continuously and uniformly. Besides, it is presented that the damping coefficient of damper in each storey may be optimized on the basis of the storey drift angles of the frame structure, and the optimum formula of the damping coefficient of damper in each storey is developed.
\end{abstract}

\section{Introduction}

The earthquake destructive to human society is very strong. Traditional seismic structure by changing the structure stiffness and mass distribution is to strengthen the structural seismic ability. Energy dissipation damping of structure is a new kind of advanced technology, which has been presented and widely used in recent years. In the structure, the energy dissipation devices are installed to consume and absorb seismic energy input in structure, reduce the seismic response of structure, thus improve the structure seismic capability.

With the dampers installed in structure, the damping ratio of structure is increased, but the damping matrix of the structure vibration equation is no longer orthogonal to vibration mode. Therefore, the normal vibration mode decomposition method is not suitable for the solution of the vibration differential equation of seismic action. Many scholars carried out extensive research for the problem. In 2004, on the basis of the model of space truss structure, Shang Yuchuan etc. derived the additional damping matrix and dynamic balance equation of the damping structure installing the viscous damper, and added the nonlinear dynamic analysis function for the damping structure in the tall building structure dynamic analysis program HBTA [1]. In 2005, Yan-tao Xue etc. put forward the solution of nonlinear vibration equation of structure with viscous dampers, which was adopted to study the single degree of freedom nonlinear dynamic response characteristics of structure with viscous dampers [2]. In 1999, Ou Jinping etc. researched the application of forced decoupling method for the vibration equation with nonorthogonal damping matrix, and presented that the damping of damper may be attached to structural modal damping ratio in the vibration mode decomposition response spectrum method [3, 4]. In 2000, Xu Zhaodong adopted Kelvin model to describe energy consumption characteristics of damper, and employed the state space method to describe the vibration equation of passive control structure, then solved the equation using MATLAB SIMULINK module. In 2005, Jiang Tong improved nonlinear viscous damping spectrum method of structural seismic response, and verified its feasibility by time history analysis method 
[6].

With the widely application of the damper, many scholars have put forward control function to optimize arrangement of dampers in the structure according to the structure functional requirement, such as control function of the storey drift angle, modal control function, etc. In 1999, Zhou Yun presented the optimized design scheme according to the performance and characteristics of viscoelastic damping structure, such as optimization design method of the storey drift angle as control function [7, 8]. In 2001, Huang Mingfeng determined the number of dampers in each storey of damping structure by genetic algorithm (GA), and gave evaluation function according to the characteristics of damper and the requirement of seismic structure, thus concluded the optimization arrangement scheme of dampers [9].

In this paper, direct integral method of state equation is raised to solve the vibration equation of frame structure with viscous dampers, which the seismic response and seismic action are researched of frame structure with viscous dampers, and the optimal damping coefficient of dampers in the structure is analyzed.

\section{Direct Integral Method of State Equation}

Seismic Response. Linear viscous dampers are arranged in frame structure. The damping force of the damper is as follows:

$$
F_{d}=-C_{d} V
$$

where, $\quad F_{d}=$ damping force of linear viscous damper

$C_{d}=$ damping coefficient of linear viscous damper

$V=$ relative velocity of both ends of linear viscous damper

The vibration equation of the frame structure with the dampers is given by

$$
[M]\{\ddot{x}\}+[C]\{\dot{x}\}+\left[C_{d}\right]\{\dot{x}\}+[K]\{x\}=-[M]\{1\} \ddot{x}_{g}
$$

where, $[M],[C]$ and $[K]$ is respectively mass matrix, damping matrix and stiffness matrix of structure itself. $\left[C_{d}\right]$ is the additional damping matrix of dampers in the structure. $\{x\}$ is displacement vector of structure storey relative to the foundation of structure itself. $\ddot{x}_{g}$ is the ground acceleration time history.

Assuming that $\{x\}=[\phi]\{q\}$, Eq. 2 may be transformed into

$$
[\bar{M}]\{\ddot{q}\}+[\bar{C}]\{\dot{q}\}+[\bar{K}]\{q\}=-[\phi]^{\mathrm{T}}[M]\{1\} \ddot{x}_{g}
$$

where, $\quad[\bar{M}]=[\phi]^{\mathrm{T}}[M][\phi]$

$$
\begin{aligned}
& {[\bar{C}]=[\phi]^{\mathrm{T}}\left([C]+\left[C_{d}\right]\right)[\phi]} \\
& {[\bar{K}]=[\phi]^{\mathrm{T}}[K][\phi]} \\
& {[\phi]=\text { structural vibration modal matrix }} \\
& \{q\}=\text { regular coordinate vector }
\end{aligned}
$$

Assuming that

$$
\{Z\}=\left\{\begin{array}{l}
\{q\} \\
\{\dot{q}\}
\end{array}\right\},
$$

Adding the equation, $[\bar{M}]\{\dot{q}\}-[\bar{M}]\{\dot{q}\}=\{0\}$, Eq. 3 may be transformed into the following state equation.

$$
\{\dot{Z}\}=[A]\{Z\}+\{P(t)\}
$$


where,

$$
\begin{aligned}
& {[A]=\left[\begin{array}{cc}
\{0\} & \{I\} \\
-[\bar{M}]^{-1}[\bar{K}] & -[\bar{M}]^{-1}[\bar{C}]
\end{array}\right]} \\
& \{P(t)\}=\left\{\begin{array}{c}
\{0\} \\
-[\bar{M}]^{-1}[\phi]^{\mathrm{T}}[M]\{1\}
\end{array}\right\} \ddot{x}_{g}
\end{aligned}
$$

Taking the structure initial state $\left\{Z_{0}\right\}=\{0\}$, Eqs.4 may be solved to

$$
\{Z\}=\int_{0}^{t} e^{[A](t-\tau)}\{P(\tau)\} \mathrm{d} \tau
$$

Calculating of the Eq. 5 by numerical integration, and assuming that $\Delta t=t_{k+1}-t_{k}$, the solution for Eq. 5 may be

$$
\begin{aligned}
\left\{Z_{k+1}\right\} & =\int_{0}^{t_{k+1}} e^{[A]\left(t_{k+1}-\tau\right)}\{P(\tau)\} \mathrm{d} \tau \\
& =e^{[A]\left(t_{k+1}-t_{k}\right)} \int_{0}^{t_{k}} e^{[A]\left(t_{k}-\tau\right)}\{P(\tau)\} \mathrm{d} \tau+\int_{t_{k}}^{t_{k+1}} e^{[A]\left(t_{k+1}-\tau\right)}\{P(\tau)\} \mathrm{d} \tau \\
& =[\varphi(\Delta t)]\left\{Z_{k}\right\}+\int_{t_{k}}^{t_{k+1}} e^{[A]\left(t_{k+1}-\tau\right)}\{P(\tau)\} \mathrm{d} \tau
\end{aligned}
$$

where, $[\varphi(\Delta t)]=e^{[A] \Delta t}=[I]+[A] \Delta t+\frac{[A]^{2} \Delta t^{2}}{2 !}+\frac{[A]^{3} \Delta t^{3}}{3 !}+\cdots+\frac{[A]^{(n-1)} \Delta t^{(n-1)}}{(n-1) !}+\cdots$

From the above calculation, the following equations may result.

$$
\begin{aligned}
& \left\{\dot{Z}_{k+1}\right\}=[A]\left\{Z_{k+1}\right\}+\left\{P\left(t_{k+1}\right)\right\} \\
& \left\{q_{k+1}\right\}=\left[H_{q}\right]\left\{Z_{k+1}\right\} \\
& \left\{\dot{q}_{k+1}\right\}=\left[H_{v}\right]\left\{Z_{k+1}\right\} \\
& \left\{\ddot{q}_{k+1}\right\}=\left[H_{v}\right]\left\{\dot{Z}_{k+1}\right\}
\end{aligned}
$$

where, $\left[H_{q}\right]=[[I] \quad[0]]$

$$
\left[H_{v}\right]=[[0] \quad[I]]
$$

Seismic response of structure, $\{x\},\{\dot{x}\}$ and $\{\ddot{x}\}$ may be solved according to the above equations. Practical Calculation of Seismic Action. Due to the damping of traditional aseismic structure smaller, the damping effect may be ignored when calculating seismic action, which may be taken as

$$
\{F\}=[K]\{x\} \approx-[M]\left(\{\ddot{x}\}+\left\{\ddot{x}_{g}\right\}\right)
$$

where, $\{F\}=$ seismic action vector of storey of structure.

With dampers installed in the structure, the structural damping may be generally larger, so the damping effect may not be ignored, and the seismic action may be taken as

$$
\{F\}=[K]\{x\}
$$

The following Eq. 13 may be derived from Eq. 12.

$$
\{F\}=[M][\phi]\left[\omega^{2}\right]\{q\}
$$

where, $\left[\omega^{2}\right]=\operatorname{diag}\left(\omega_{j}^{2}\right) \quad(j=1,2, \ldots n)$

$\omega_{j}=$ natural vibration frequency of the $j t h$ vibration mode of the structure

The seismic action of the $j$ th vibration mode may result as follows: 


$$
\left\{F_{j}\right\}=[M]\left\{\phi_{j}\right\} \omega_{j}^{2} q_{j}
$$

where, $\left\{F_{j}\right\}=$ seismic action vector of the $j$ th vibration mode of structure.

From Eq. 14, the seismic action of the $j t h$ vibration mode of the $i t h$ storey may be as follows:

$$
F_{j i}=M_{i} \phi_{j i} \omega_{j}^{2} q_{j}
$$

where, $\quad F_{j i}=$ seismic action of the $j t h$ vibration mode of the $i t h$ storey of structure

$\phi_{j i}=$ the $j$ th vibration mode of the $i t h$ storey of structure

$q_{j}=$ regular coordinate vector of the $j t h$ vibration mode of structure

$M_{i}=$ mass of the $i t h$ storey of structure

The damping ratio of design response spectrum may be usually $0.02 \sim 0.30$, but the equivalent damping ratio of structure installing the dampers may be more than 0.3 . Therefore the method of design response spectrum of calculation seismic action should be revised according to the following two conditions.

The equivalent damping ratio may be calculated as follows:

$$
\xi_{j}=\frac{\left\{\phi_{j}\right\}^{T}[C]\left\{\phi_{j}\right\}}{2 \omega_{j}\left\{\phi_{j}\right\}^{T}[M]\left\{\phi_{j}\right\}}
$$

(1) When $\xi_{j}<1$

Considering $\left|q_{j}\right|_{\max }=\gamma_{j} \alpha_{j} g, \quad F_{j i}$ may be calculated as

$$
F_{j i}=\alpha_{j} \gamma_{j} \phi_{j i} G_{i} \quad(j, i=1,2, \ldots n)
$$

where, $\quad q_{j}=-\frac{1}{\omega_{j}^{\prime}} \int_{0}^{t} \gamma_{j} \ddot{x}_{g}(\tau) e^{-\xi_{j}^{\prime} \omega_{j}^{\prime}(t-\tau)} \sin \omega_{j}^{\prime}(t-\tau) \mathrm{d} \tau$

$$
\begin{aligned}
\omega_{j}^{\prime} & =\omega_{j} \sqrt{1-\xi_{j}^{2}} \\
\xi_{j}^{\prime} & =\frac{\xi_{j}}{\sqrt{1-\xi_{j}^{2}}} \\
\gamma_{j} & =\frac{\left\{\phi_{j}\right\}^{T}[M]\{1\}}{\left\{\phi_{j}\right\}^{T}[M]\left\{\phi_{j}\right\}} \\
\gamma_{j} & =\text { vibration mode participation coefficient } \\
G_{i} & =\text { representative value of gravity load } \\
\alpha_{j} & =\text { seismic influence coefficient of the } j t h \text { vibration mode }
\end{aligned}
$$

For the structure of larger damping ratio $\left(0.3<\xi_{j}<1\right), \alpha_{j}$ can be determined according to $\mathrm{T}_{j}^{\prime}=\frac{2 \pi}{\omega_{j}^{\prime}}$ and $\xi_{j}^{\prime}=\frac{\xi_{j}}{\sqrt{1-\xi_{j}^{2}}}$.

(2) When $\xi_{j} \geq 1$

According to the site category and design earthquake group, 3 types of acceleration time history curve may be selected, namely two actual earthquake acceleration time history curve and an artificial simulated acceleration time history curve. On the basis of direct integral method of state equation presented in the paper, regular coordinates of damping energy dissipation structure and corresponding aseismic structure may be calculated separately. Then, the absolute value of each order regular coordinate of both structures is taken the maximum respectively in the calculation 
results of the 3 types of waves. The $j$ th order coefficient of vibration damping $\beta_{j}$ is defined as

$$
\beta_{j}=\frac{\left|q_{j}\right|_{\max }}{\left|\bar{q}_{j}\right|_{\max }} \quad(j=1,2, \ldots n)
$$

where,

$\left|q_{j}\right|_{\max }=$ maximum of absolute value of the $j$ th order regular coordinates of damping energy dissipation structure

$\left|\bar{q}_{j}\right|_{\max }=$ maximum of absolute values of the $j t h$ order regular coordinates of the corresponding seismic structure

From Eq. 15, seismic action of the $j$ th vibration mode of the $i t h$ storey may be expressed as

$$
\begin{aligned}
& F_{j i}=M_{i} \phi_{j i} \omega_{j}^{2}\left|q_{j}\right|_{\max }=\beta_{j} M_{i} \phi_{j i} \omega_{j}^{2}\left|\bar{q}_{j}\right|_{\max } \\
& \left|\bar{q}_{j}\right|_{\max }=\frac{1}{\omega_{j}}\left|\int_{0}^{t} \gamma_{j} \ddot{x}_{g}(\tau) e^{-\xi_{i} \omega_{i}(t-\tau)} \sin \omega_{j}(t-\tau) \mathrm{d} \tau\right|_{\max }=\gamma_{j} \alpha_{j} g
\end{aligned}
$$

where,

From Eq. 19, $F_{j i}$ may be expressed as follows:

$$
F_{j i}=\beta_{j} \alpha_{j} \gamma_{j} \phi_{j i} G_{i} \quad(j, i=1,2, \ldots n)
$$

where, $\alpha_{j}=$ seismic influence coefficient of the $j t h$ vibration mode of the corresponding aseismic structure

$$
G_{i}=M_{i} g
$$

\section{Structure Analysis}

A 10 storey concrete frame structure is designed, whose bottom storey height is $4.5 \mathrm{~m}$, the rest storey height is $3.3 \mathrm{~m}$, and total height of the structure is $34.2 \mathrm{~m}$. The structure plane layout is shown in Fig. 1. The seismic precautionary intensity of the structure is degree $8(0.30 \mathrm{~g})$, the earthquake group is 2 , and the seismic precautionary category is $\mathrm{C}$. The building structure adopts $\mathrm{C} 30$ concrete construction. Dead load standard value of building roof is $10 \mathrm{kN} / \mathrm{m}^{2}$, and live load standard value is $2 \mathrm{kN} / \mathrm{m}^{2}$. Each beam section size is $300 \mathrm{~mm} \times 650 \mathrm{~mm}$, each slab thickness is $100 \mathrm{~mm}$, and each column section size is $600 \mathrm{~mm} \times 750 \mathrm{~mm}$. The viscous dampers are installed respectively according to Fig. 2. Each damping coefficient $C_{d}$ is $5 \times 10^{4} \mathrm{kN} \cdot \mathrm{s} / \mathrm{m}$ in Fig. 2.

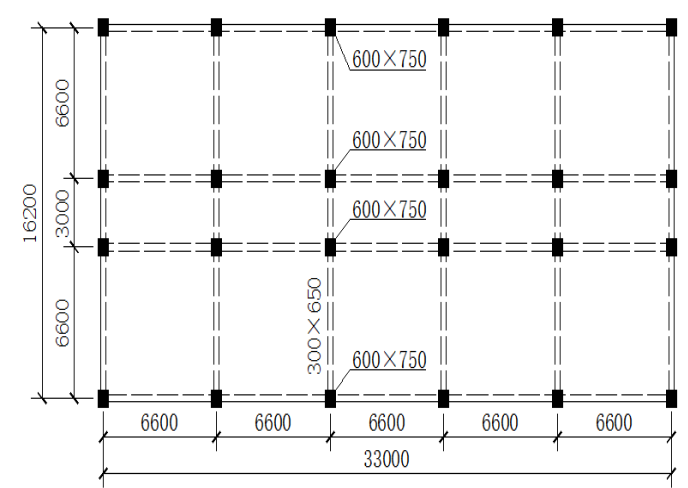

Fig. 1 Plane layout of frame structure.

Each frame structure in Fig. 2 is respectively subjected to 4 types of seismic wave, namely 
Oroville wave for site type 1, El-Centro wave for site type 2, Hollywood Storage wave for site type 3 and Tian Jing of China wave for site type 4, and each seismic peak acceleration is 110 gal. Seismic response of each structure subjected to the seismic wave is researched in the paper.

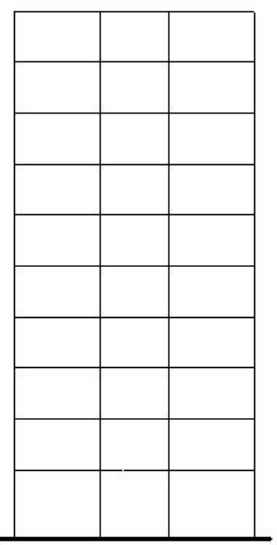

(a)

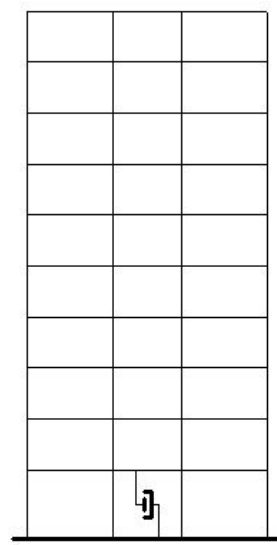

(b)

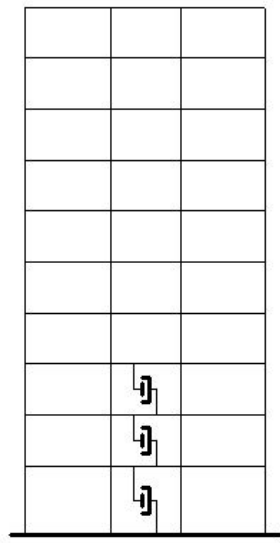

(c)

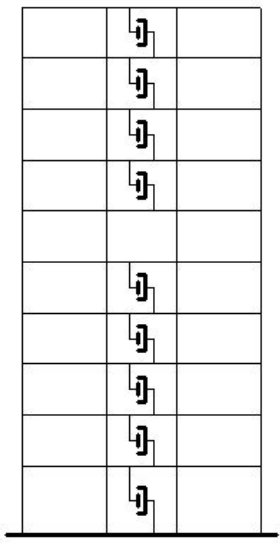

(d)

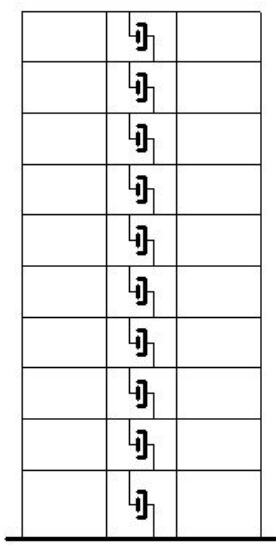

(e)

Fig. 2 Calculation diagram of frame structure.

Natural Vibration Period of Structure. The natural vibration period may be calculated and shown in Table 1.

Table 1. Structural vibration period (s).

\begin{tabular}{|c|c|c|}
\hline The first period & The second period & The third period \\
\hline 1.378 & 0.4627 & 0.2818 \\
\hline
\end{tabular}

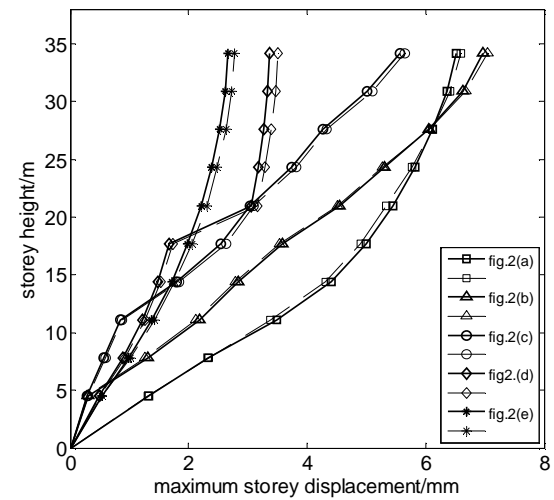

(a) Oroville wave

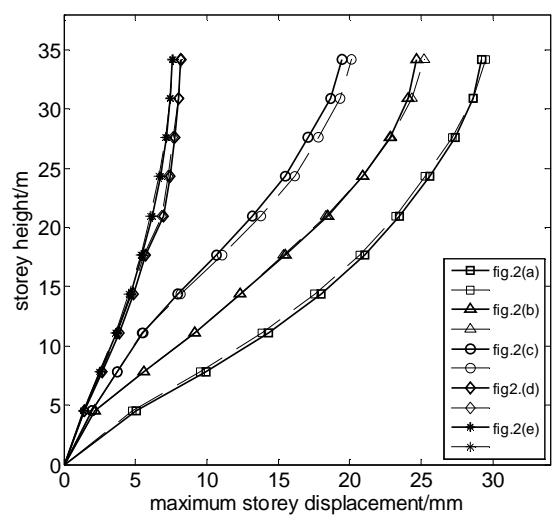

(c) Hollywood Storage wave

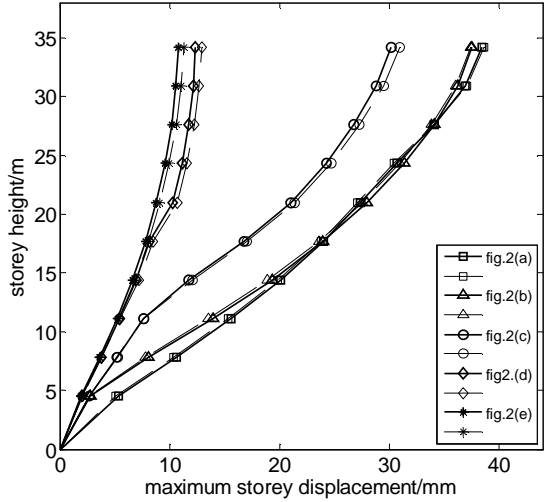

(b) El-Centro wave



(d) Tian Jing of China wave

Fig. 3 Storey maximum displacement relative to the base of structure itself. 
Maximum Displacement Response Relative to Base of Structure Itself. In the paper, the maximum displacement response relative to base of structure itself may be calculated adopting two methods respectively, namely the direct integral method of state equations and the SAP2000 software. The calculation results have been showed in Fig. 3 respectively.

In Fig. 3, the bold line "-" expresses the calculation result of the direct integral method of state equation, and dotted line "--." shows that the result of SAP2000 software. This figure shows that the calculation result of both methods may be basic agreement, and the error is within $5 \%$.

Fig. 3 also indicates the following results.

(1) When the viscous damper is only arranged in the first storey of structure, shown in Fig. 2(b), the maximum displacement responses of storeys except the top storey may be smaller than those of the corresponding aseismic structure shown in Fig. 2(a), but the maximum displacement response of top storey may be more than that of top storey of the corresponding aseismic structure.

(2) When viscous dampers are installed in the bottom three storeys, shown in Fig. 2(c), the maximum displacement response of each storey compared with that of the corresponding aseismic structure is reduced.

(3) When viscous damper is uniformly arranged in each storey, shown in Fig. 2(e), the maximum displacement response of each storey relative to that of the corresponding seismic structure, shown in Fig. 2(a), may reduce more, and the damping effect is obvious.

(4) When viscous dampers are uniformly arranged except the 6th storey, shown in Fig. 2(d), the maximum displacement response of the 6th storey will suddenly increase.

Maximum Storey Drift Angle of Structure. In the paper, maximum drift angle of each storey of structure may be respectively calculated according to the direct integral method of state equation and the SAP2000 software. The calculation results have been showed in Fig. 4.

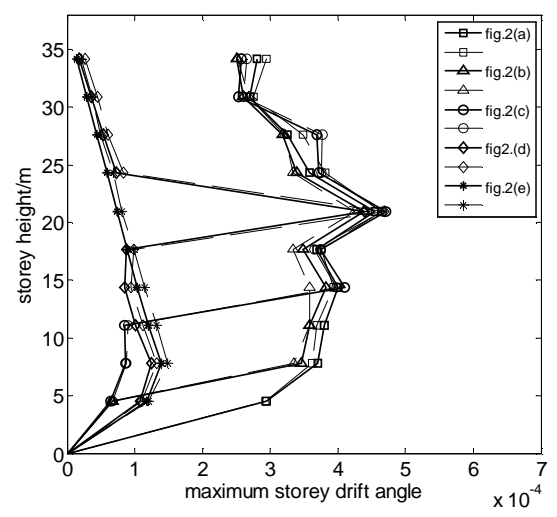

(a) Oroville wave

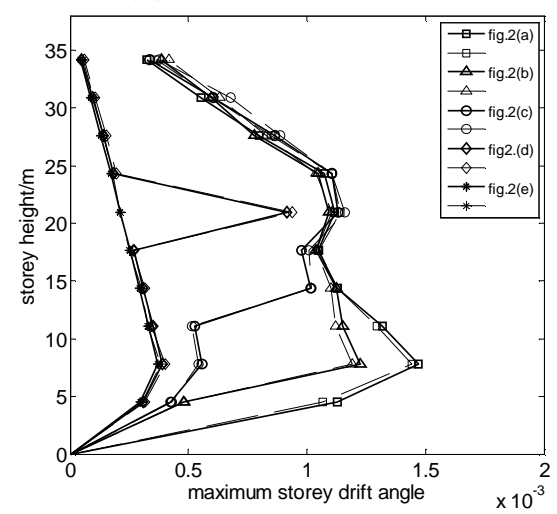

(c) Hollywood Storage wave

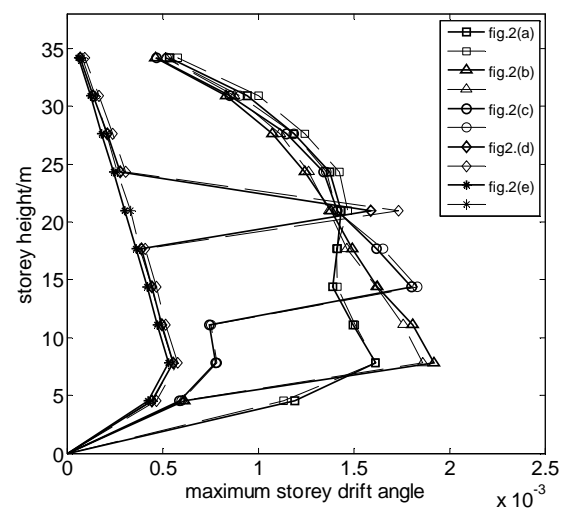

(b) El-Centro wave

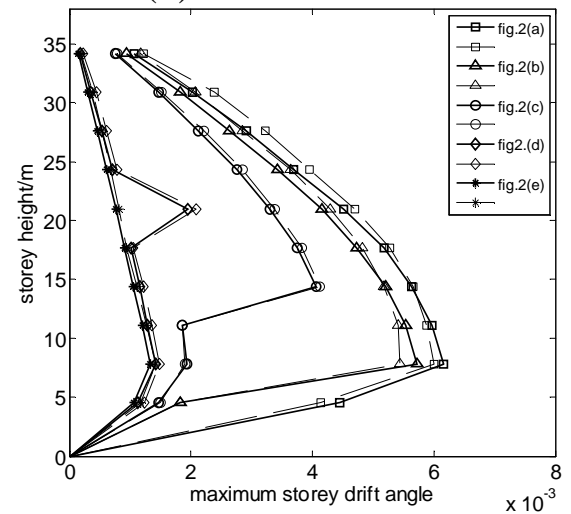

(d) Tian Jing of China wave

Fig. 4 Maximum storey drift angle of structure.

Fig. 4 may indicate the following results. The bold line "-" expresses the calculation result of the direct integral method of state equation, and dotted line "--." shows that the result of SAP2000 software. 
(1) For the storeys installing dampers, the maximum storey drift angle relative to that of the corresponding aseismic structure may be reduced significantly. But for the storeys without dampers, the maximum storey drift angle may be reduced little, and may even be increased.

(2) When viscous damper is uniformly arranged in each storey, maximum drift angle of each storey relative to that of the corresponding aseismic structure may be significantly decreased, but the drift angles of the upper storeys may generally be less than those of the lower storeys, which shows that viscous dampers installed uniformly can significantly reduce the seismic response, and the damping effect is more significant.

(3) When viscous dampers are uniformly arranged except the 6th storey, the maximum drift angle of the 6th storey may suddenly increase, which may even be more than that of the 6th storey of the corresponding aseismic structure.

As indicates that viscous dampers should be installed continuously and uninterruptly in the storeys.

Optimization of Damping Coefficients of Viscous Dampers. The above analysis shows that when the dampers are installed uniformly and continuously in the storeys, the damping effect may be significant, and the drift angles of upper storeys may be much less than those of the lower storeys. Therefore, when all storey drift angles meet the seismic request, the drift angles of the upper part of storey may be appropriately increased.

Thus, it may be presented in the paper that damping coefficients of viscous dampers in storeys may be optimized on the basis of drift angles of storeys in which viscous dampers are installed uniformly and continuously. The damping coefficients of viscous dampers may be optimized as follows.

$$
C_{i+1}=C_{i} \frac{\Delta \theta_{i+1}}{\Delta \theta_{i}} \quad(i=1,2, \ldots, n-1)
$$

where, $\quad C_{i+1}=$ damping coefficient of viscous damper of the $(i+1)$ th storey

$C_{i}=$ damping coefficient of viscous damper of the $i$ th storey

$\Delta \theta_{i+1}=$ maximum drift angle of the $(i+1)$ th storey

$\Delta \theta_{i}=$ maximum drift angle of the ith storey

According to Eq. 23, the damping coefficients of viscous dampers installed in structure may be optimized. On the basis of the damping coefficient optimized of each storey, the maximum displacement of each storey relative to the base of structure itself and the maximum drift angle of each storey may be calculated, and the calculation results are shown in Fig. 5 and Fig. 6.

Fig. 5 and Fig. 6 indicate that the difference of each maximum displacements of storey is reduced, and the maximum drift angles of storeys may be close, so the storey damping distribution is more reasonable.

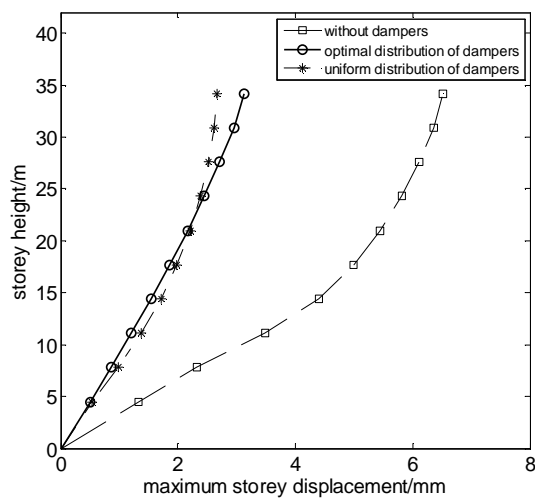

(a) Oroville wave



(b) El-Centro wave 


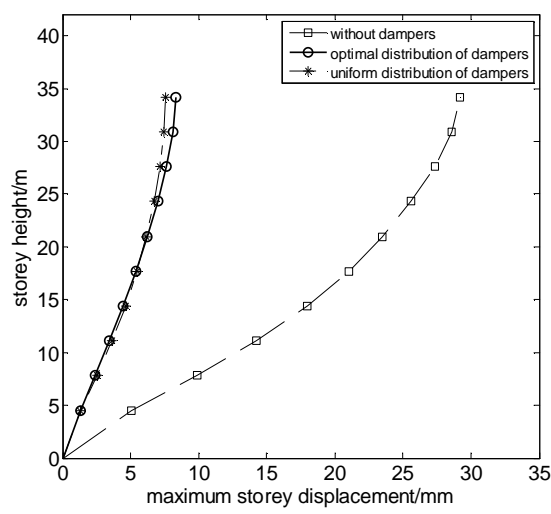

(c) Hollywood Storage wave

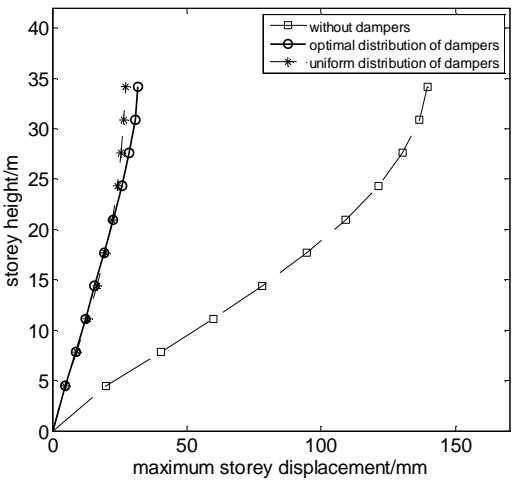

(d) Tian Jing of China wave

Fig. 5 Maximum displacement of each storey relative to the base of structure.

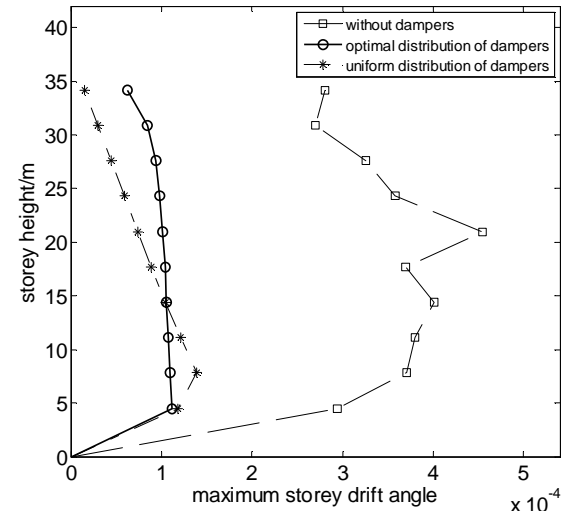

(a) Oroville wave



(c) Hollywood Storage wave



(b) El-Centro wave

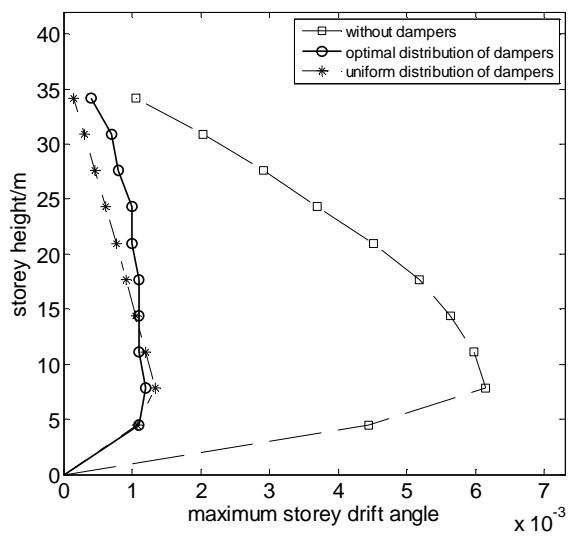

(d) Tian Jing of China wave

Fig. 6 Maximum drift angle of each storey.

Practical Calculation of Seismic Action. After the damping coefficients of viscous dampers in the structure are optimized, the equivalent damping ratio of each order vibration is more than 1 according to Eq. 16, so the seismic action may be calculated on the basis of Eq. 21, which of the first three vibration modes of the damping structure and the corresponding aseismic structure may be shown in the Fig. 7 respectively. 


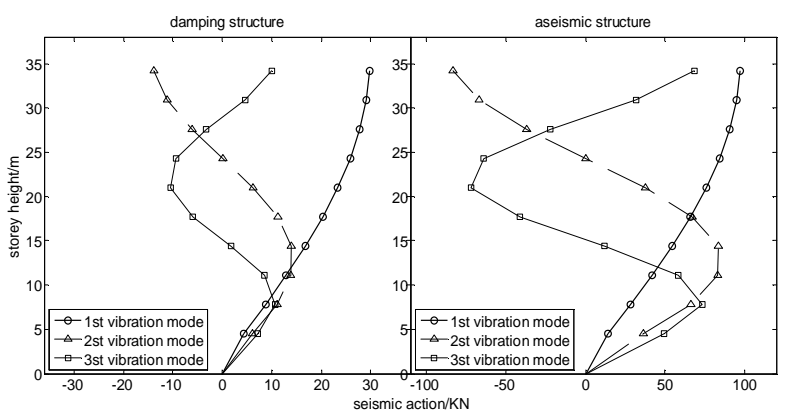

(a) site type 1



(c) site type 3

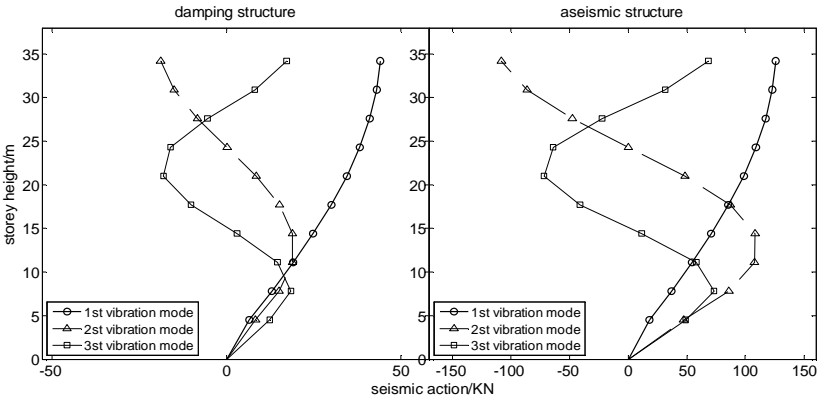

(b) site type 2

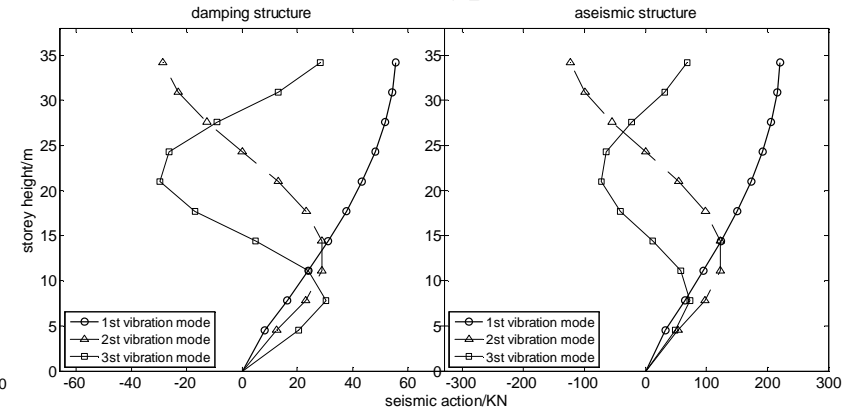

(d) site type 4

Fig. 7 Seismic action.

Fig. 7 indicates that the seismic action of damping structure installing damper is much less than that of the corresponding aseismic structure.

\section{Conclusion}

In this paper, seismic responses of the linear viscous damping energy dissipation structure are analyzed. The conclusion may be as follows.

(1) Seismic response of the linear viscous damping energy dissipation structure is analyzed according to the direct integral method of state equation, and the results of the analysis are compared with those of SAP2000 software, which shows that the error of the two methods is within $5 \%$, thus direct integral method of state equation has enough calculation precision and may meet the request of engineering.

(2) The influence of the arrangement of viscous dampers in the structure on seismic response is more significant. The drift angles of storey installing the damper in, may be decreased significantly. But the drift angle of storey not installing the damper in, may be larger. As may indicate that viscous dampers in the structure should be arranged continuously and uninterruptly, but each damping coefficient of structure may gradually be changed along the storey.

(3) When viscous dampers are uniformly arranged in structure, the damping effect is more effective. But the damping coefficient in each storey may be optimized on the basis of the drift angles of storey installing the dampers in uniformly and continuously. After the damping coefficients optimized, the maximum drift angles of lower storeys may be close, and the difference of the maximum drift angles of the upper storeys and those of the lower storeys may be reduced.

(4) In the paper, the practical calculation method of seismic action of linear viscous damping energy dissipation structure is presented.

\section{References}

[1] Y. C. Tang, Y. L. Zhang, T. S. Zhang. Nonlinear dynamic analysis of structures with viscous dampers, Eng. Mech. 21(01) (2004) 67-71+158.

[2] Y. T. Xue, X. Han. Time-history analysis of earthquake response on structure with non-linear fluid viscous damper, Earthq. Resist. Eng. Retrof. 27(02) (2005) 40-45. 
[3] J. P. Ou, B. Wu, Y. Long. Aseismic design methods of passive energy dissipation systems, Earthq. Eng. Eng. Vibr. 18(02) (1998) 98-107.

[4] J. P. Ou, B. Wu, Y. Long. Seismic design approaches of passive energy dissipation systems, Earthq. Eng. Eng. Vibr. 1999,(02):55-62.

[5] Z. D. Xu, Y. Q. Guo, Y. Zhou, H. T. Zhao. Concrete frame structure dynamic analysis on the basis of SIMULINK, Earthq. Resist. Eng. (04) (2000) 18-22.

[6] T. Jiang, L. He. Analysis of vibration reduction effects for energy dissipation structures with non-linear viscous dampers, World Earthq. Eng. 21(02) (2005) 57-63.

[7] Y. Zhou, Z. D. Xu, X. S. Deng. Optimum installation of the dampers in the viscoelastic structures, Word Inform. Earthq. Eng. 14(03) (1998) 15-20.

[8] Z. D. Xu, Y. Zhou, H. T. Zhao. The optimum design of the viscoelastic structure, J. Xi'an Univ. Arch. Tech. (Natural Science Edition), (03) (1999) 44-46+50.

[9] M. F. Huang, J. X. Tang. Optimum installation of the viscoelastic dampers for the tower structures, J. Univ. Sci. Tech. (Natural Science Edition), (11) (2011) 73-75.

[10] M. C. Constantinou, P. Tsopelas, W. Hammel, A. N. Sigaher. Toggle-Brace-Damper Seismic Energy Dissipation Systems, J. Struct. Eng. 127(2) (2001) 105-112.

[11] J. M. Kelly, et al, Mechanisms of energy absorption in special deviees for use in earthquake, Earthq. Eng. Struct. Dyn. 22 (1996) 223-241.

[12] R. Villaverde, Explanation for the numerous upper floor collapses during the 1985 Mexieo city Earthquake, Earthq. Eng. Struct. Dyn. 22 (1991) 223-241.

[13] A. M. Reinhom, C. Li and M. C. Constantlnou, Experimental and analytical investigation of seismic retrofit of structures with supplemental damping patrl-flnid viscous damping devicesf. NCEER-95-0001, J. State University of New York at Buffalo, New York, 1995.

[14] M. Miyazaki, Y. Mitsusaka. Design of Building with 20\% or Greater Damping, Tenth World Conference, Earthquake Engineering, Madrid, 1992.

[15] T. T. Soong, G. F. Dargush. Passive Energy Dissipation Systems in Structural Engineering, Eng. Struct. 23(3) (1997) 8-12.

[16] P. Dougas, M. Taylor, C. Constantinou, Fluid Dampers for Application of Seismic Energy Dissipation and Seismic isolation, Eng. Struct. 25(6) (1998) 10-12.

[17] T. T. Soong, G. F. Dargush. Passive Energy Dissipation System in Structural Engineering, J. State University of New York at Buffalo, 1997.

[18] J. K. Kim, H. H. Choi, K. W. Min, Performance-based design of added viscous dampers using capacity Spectrum method, J. Earthq. Eng. 7(1) (2003) 1-24.

[19] J. K. Kim, H. H. Choi. Displacement-based design of supplemental dampers for seismic retrofit of a framed structure, J. Struct. Eng. 132(6) (2006) 873-883.

[20] F. Hejazi, I. Toloue, M. S. Jaafar, J. Noorzaei. Optimization of Earthquake Energy Dissipation System by Genetic Algorithm, Comput. Aid. Civil Infrastruct. Eng. 28(10) (2013) 2-13.

[21] F. Hejazi, A. Zabihi, M. S. Jaafar. Development of elasto-plastic viscous damper finite element model for reinforced concrete frames, Soil Dyn. Earthq. Eng. 65(7) (2014) 27-39.

[22] H. Qian, et al. Recentering Shape Memory Alloy Passive Damper or Structural Vibration Control, Math. Prob. Eng. 20(16) (2013) 13-25.

[23] S. M. Lim, Z. Yun, X. S. Deng. Optimization analysis for high-rise structure with viscous 
energy-dissipation story, Civil Eng. J. 46(10) (2013) 71-81.

[24] G. B. Warburton, S. R. Soni. Errors in response calculations for non-classically damped structures, Earthq. Eng. Struct. Dyn. 5(4) (1977) 365-376.

[25] X. Y. Zhou, R. F. Yu, D. Dong. Complex mode superposition algorithm for seismic responses of non-classically damped linear MDOF system, Earthq. Eng. (4) (2004) 597-641. 